\title{
Enhanced Cooling Process of Furnace Using Vortex Tube Cooling Device
}

\author{
Mohd Hazwan Yusof ${ }^{l, *}$, Muhammad Fadhli Suhaimi ${ }^{l}$, Izzat Muhammad Azmi ${ }^{1}$, Wan \\ Sharuzi Wan Harun, and Mohamad Firdaus Basrawi ${ }^{l}$ \\ ${ }^{1}$ Faculty of Mechanical Engineering, Universiti Malaysia Pahang, 26600, Pekan, Pahang.
}

\begin{abstract}
A furnace is a heating device, which is used for heating samples up to $1350^{\circ} \mathrm{C}$. The conventional method to reduce the temperature of the furnace to room temperature requires more than 8 hours. Therefore, a vortex tube cooling device is used to enhance the cooling process. The vortex tube is a small cooling device that uses compressed gas to produce cold flow. In this study, 3 cooling methods were compared; the conventional method, room temperature compressed gas cooling method, and vortex tube cooling method. From the results, it is clear that the vortex tube is able to enhanced the cooling process. Comparing to the conventional method, the vortex tube can reduce the temperature 2-hour faster.
\end{abstract}

\section{Introduction}

The vortex tube (also called as Ranque Hilsch vortex tube) is a mechanical device that separates a compressed air into cold and hot streams without any moving parts or chemical reactions. It consists of cold exit, tangential nozzle, vortex chamber, tube, control valve, and a hot exit, as shown in Fig. 1.

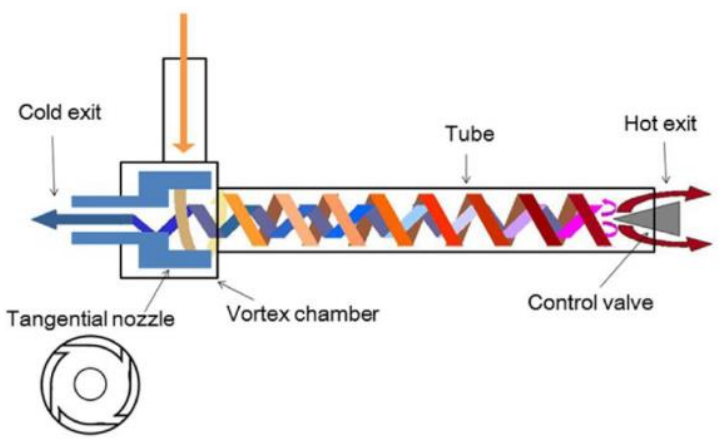

Fig. 1. Schematic diagram of vortex tube [1].

S. E. Rafiee et al. [2] investigated the differences cone angle on convergence vortex tube that $15^{\circ}, 20^{\circ}, 25^{\circ}$ and $30^{\circ}$. They reported that cone angle, $\alpha=30^{\circ}$ leads to $50.60 \%$ higher heating performance at the cold flow ratio of 0.75 and provides higher cooling efficiency

\footnotetext{
* Corresponding author: mohdhazwan@ump.edu.my
} 
which is $43.76 \%$. G. S. Kumar et al. reported that the best cone angle is $20^{\circ}$ [3]. However, S. E. Rafiee et al. [2] reported the cone angle, $\alpha=30^{\circ}$ is the best cone angle. K. Devade and A. Pise [4] studied the effect of cone angle $30^{\circ}, 45^{\circ}, 60^{\circ}$ and $90^{\circ}$ in their experiment. From their study, they reported that angle of $45^{\circ}$ is the best cone angle because it gives maximum cooling effect while for $60^{\circ}$ angle provided the better heating effect. B. Markal et. al. [5] investigated four different cone angle, $\alpha=30^{\circ}, 45^{\circ}, 60^{\circ}, 90^{\circ}$. It observed that the effect of the cone angle on the performance changes depends to the value of the length to inner diameter ratio, L/D. The result shows that the smaller angle is better to use in order to improve the performance of the vortex tube with smaller L/D. However, Y. Xue and M. Arjomandi reported different results [6]. They studied various numbers of cone angle which is $2.5^{\circ}, 3.8^{\circ}, 4.8^{\circ}, 6.7^{\circ}, 8.6$, $12.3^{\circ}, 17.9^{\circ}, 23.1^{\circ}$. In this study, the inlet pressure was varied from 2 until 4 bar to determine the optimum angle. From this figure, it is understood that the highest cooling efficiency obtained at 4 bar with a cone angle of $2.5^{\circ}$.

K. Devade and A. Pise [4] investigated the cold diameter to inner diameter ratio, $d / D$ of $0.36,0.43$ and 0.50 . The inner diameter, $\mathrm{D}$ is $14 \mathrm{~mm}$. From their study, it can be understood that the $\mathrm{d} / \mathrm{D}=7 \mathrm{~mm}$ has the highest COP $(0.18)$ when the inlet pressure is 5 bars. S. U. Nimbalkar and M. R. Muller [7] studied the energy flux separation of the vortex tube. It can be understood that at $60 \%$ of cold fraction regardless of diameter ratio and inlet pressure is the maximum performance. The highest energy flux separation achieves when the $\mathrm{d} / \mathrm{D}$ is 0.50 within the cold fraction $60 \%$ to $80 \%$. From these research, it is clear that 0.50 of diameter ratio is the optimum value of the cold exit diameter.

A furnace can produce a high-temperature heating area up to $1350^{\circ} \mathrm{C}$. A conventional method to reduce the temperature until $30^{\circ} \mathrm{C}$ usually takes more than 8 hours. Therefore, in this study, the vortex tube cooling device is used to reduce the high-temperature furnace. Three methods of the cooling process will be compared, and the cooling rate and time consumption will be clarified.

\section{Methodology}

\section{Furnace}

The furnace that was used in this experiment is shown in

Fig. 2. The specifications of the furnace are shown in

Table 1 . The furnace was heated until the temperature reached $1350^{\circ} \mathrm{C}$. The cooling process was conducted through three cooling methods, which will be explained in details later in subsection 0 . 
Fig. 2. Furnace used in the experiment.

Table 1 Furnace specifications.

\begin{tabular}{|l|l|}
\hline Model & HTF-14/200-5 \\
\hline Serial NO & $0339 / 15$ \\
\hline Temperature measurement & Thermocouple Type-R \\
\hline Date of manufactured & January 2015 \\
\hline Max Temperature & $1400^{\circ} \mathrm{C}$ \\
\hline Max constant temperature & $1350^{\circ} \mathrm{C}$ \\
\hline Power & $240 \mathrm{VAC} / 1 \mathrm{P} 50 \mathrm{HZ}$ \\
\hline
\end{tabular}

\subsection{Vortex tube}

The vortex tube is shown in Fig. 3. This vortex tube was manufactured by a company in China. It is made from stainless steel and has a length of $15 \mathrm{~cm}$. The compressed air inlet, cold flow outlet and hot flow outlet are shown in this figure, respectively. In this research, the cold flow that exits through the cold flow outlet was connected to the high-temperature furnace to reduce its temperature. This process is one of the three cooling methods.

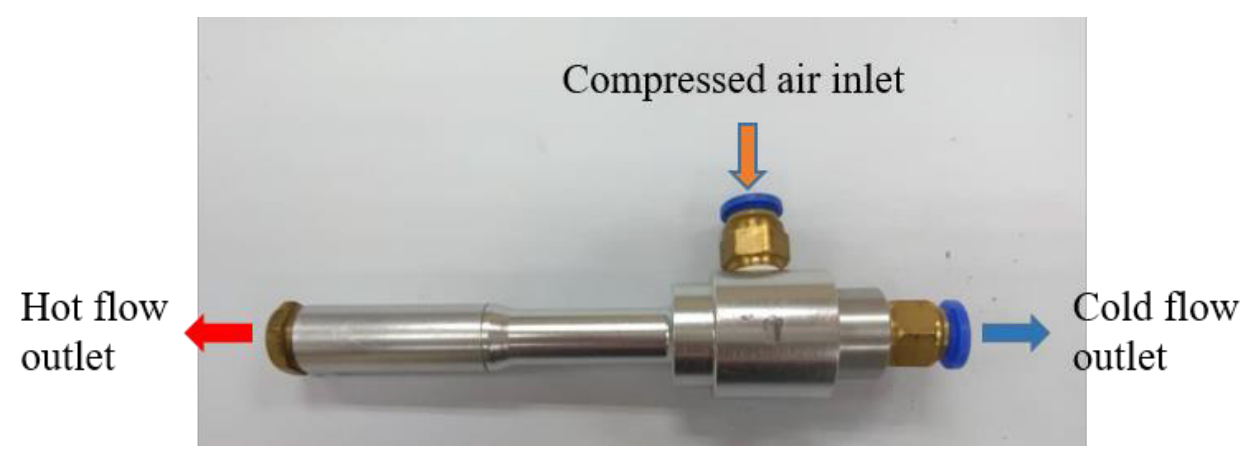

Fig. 3. Vortex tube. 


\subsection{Cooling methods and apparatus setup}

In this research, three cooling methods were applied, and the performance of the methods was compared. The three cooling methods are named Conventional method, Non-VT and VT, respectively. The details are shown in Table 2. For the conventional method, the heated furnace was leaved to be cooled naturally by the ambient air until the temperature drop to $30^{\circ} \mathrm{C}$. For Non VT and VT cooling method, an apparatus was connected to the furnace, as shown in Fig. 4. The pressure of compressed air from the compressor was regulated by a pressure regulator. Then, the flow was controlled by the control valve to flow through the vortex tube (VT flow) or not (Non VT flow). The mass flow rate and the flow temperature of the flow that enters the furnace was measured by a flow meter and thermocouple Type-K, respectively. The temperature of the furnace was measured and displayed by thermocouple Type-R and temperature display, respectively. These two devices are a built-in device of the furnace. To determine the optimum setup of the cooling process, the cold flow mass flow rate and inlet pressure for Non VT and VT cooling method were varied at 60, 80, $100 \mathrm{lpm}$ and 4, 5, 6 bar, respectively, as shown in Table 2 .

Table 2 Cooling methods comparison.

\begin{tabular}{|l|l|l|l|l|l|l|}
\hline No & $\begin{array}{l}\text { Cooling } \\
\text { method }\end{array}$ & Description & Type of gas & $\begin{array}{l}\text { Mass } \\
\text { flow rate } \\
(\mathrm{lpm})\end{array}$ & $\begin{array}{l}\text { Inlet } \\
\text { pressure } \\
\text { (gage; bar) }\end{array}$ & Temperature \\
\hline 1 & $\begin{array}{l}\text { Conventional } \\
\text { method }\end{array}$ & $\begin{array}{l}\text { Furnace is } \\
\text { leaved to be } \\
\text { cooled } \\
\text { naturally by } \\
\text { the ambient } \\
\text { air. }\end{array}$ & Ambient air & 0 & 0 & $\begin{array}{l}\text { Room } \\
\text { temperature }\end{array}$ \\
\hline 2 & Non VT & $\begin{array}{l}\text { Room } \\
\text { temperature } \\
\text { compressed air } \\
\text { is injected into } \\
\text { the furnace. }\end{array}$ & $\begin{array}{l}\text { Compressed } \\
\text { air }\end{array}$ & $\begin{array}{l}60,80, \\
100\end{array}$ & $4,5,6$ & $\begin{array}{l}\text { Room } \\
\text { temperature }\end{array}$ \\
\hline 3 & VT & $\begin{array}{l}\text { Cold flow } \\
\text { from vortex } \\
\text { tube is } \\
\text { injected into } \\
\text { the furnace. }\end{array}$ & $\begin{array}{l}\text { Compressed } \\
\text { air }\end{array}$ & $\begin{array}{l}60,80, \\
100\end{array}$ & $4,5,6$ & $\begin{array}{l}\text { Cold flow } \\
\text { temperature }\end{array}$ \\
\hline
\end{tabular}




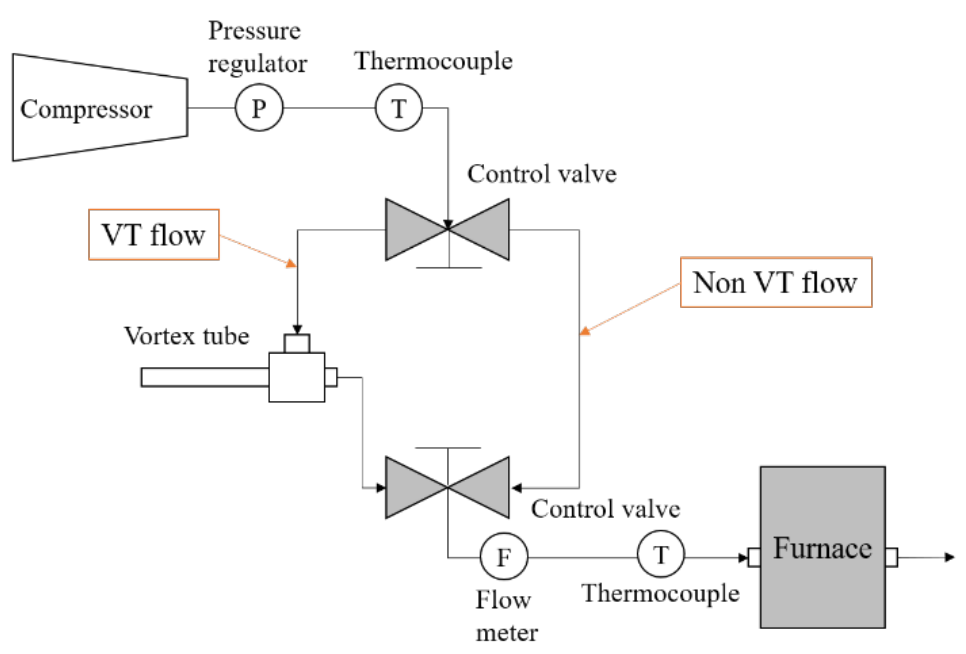

Fig. 4. Schematic diagram of the experimental setup for Non-VT and VT cooling methods.

\subsection{Governing equations}

To measure the performance of vortex tube, a temperature difference between the inlet and cold outlet was used, as shown in Eq. (1).

$$
\Delta T_{c}=T_{c}-T_{i}\left[{ }^{\circ} \mathrm{C}\right]
$$

Here, $T_{c}$ is the cold flow temperature, and $T_{i}$ is the inlet temperature.

Eq. (2) was used to measure the cooling rate. Here, $T_{n}$ represents the temperature at $n$ reading point, and $T_{n+1}$ represents the temperature at $\mathrm{n}+1$ reading point, which is 20 minutes after the temperature measurement of $T_{n}$.

$$
\dot{C}=\frac{T_{n}-T_{n+1}}{20}\left[{ }^{\circ} \mathrm{C} / \mathrm{min}\right]
$$

\section{Results and discussions}

\subsection{Performance of vortex tube}

The performance of vortex tube is measured using the temperature difference between the inlet temperature and cold flow temperature. In this research, the inlet pressure and cold flow mass flow rate were varied at 60, 80, $100 \mathrm{lpm}$ and 4, 5, 6 bar, respectively. The result for the temperature differences is shown in Fig. 5. From this figure, it is clear that increasing the cold flow mass flow rate increases the temperature difference, i.e. the lower temperature of cold flow is generated. Likewise, increasing the inlet pressure increases the temperature differences. Inlet pressure of 6 bar and cold flow mass flow rate of $100 \mathrm{lpm}$ produces the maximum temperature differences $\left(-7.23^{\circ} \mathrm{C}\right)$. 


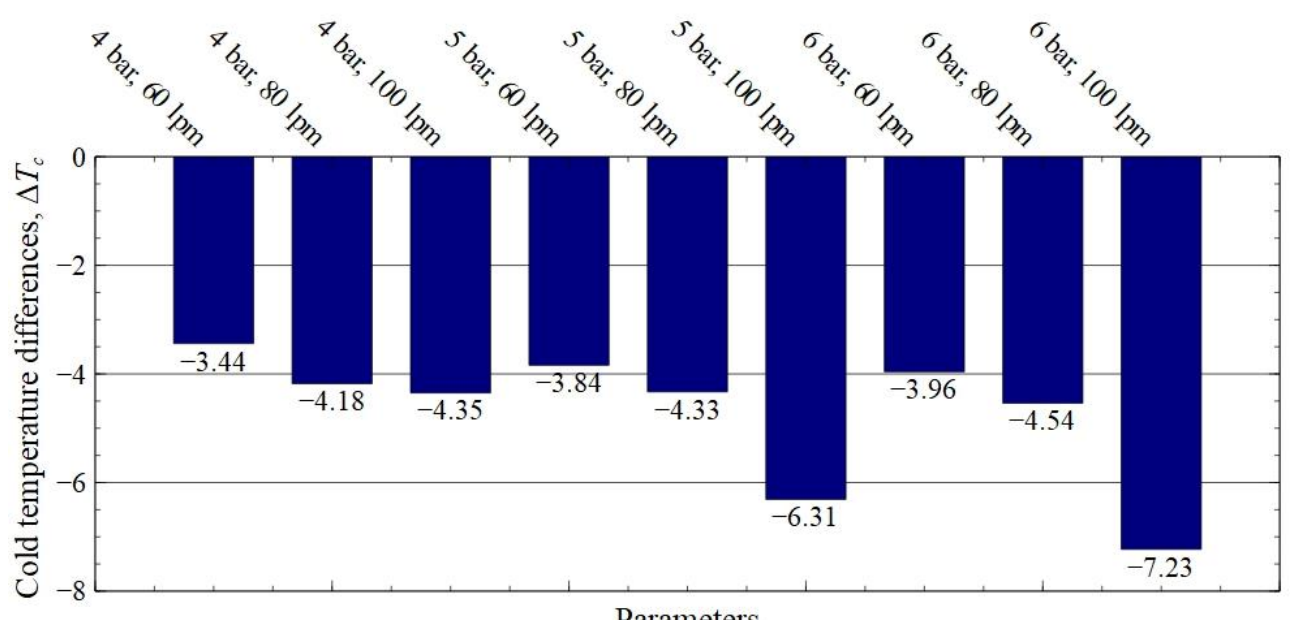

Fig. 5. Cold temperature difference, $\Delta T_{c}$ for all parameters.

\subsection{Furnace temperature and cooling rate}

As mentioned above, the inlet pressure and mass flow rate were varied at 60, 80, $100 \mathrm{lpm}$ and 4, 5, 6 bar, respectively. For comparison purpose, only the inlet pressure of 6 bar and mass flow rate of $100 \mathrm{lpm}$ will be discussed. The overall results will be discussed in subsection 0 .

Fig. 6 (a) and (b) shows the effect of cooling methods on the furnace temperature and cooling rate, respectively. As can be seen from Fig. 6 (a), the furnace temperature significantly drop when Non-VT and VT cooling methods were used. Comparing with the conventional method that has no air flow, the air flow from Non-VT and VT enhanced the heat transfer process. This allows the heat from the furnace is absorbed by the air flow, and exits the furnace. The VT cooling method reduces the furnace temperature faster than NonVT cooling method due to the lower air flow temperature. From Fig. 5, when the inlet pressure is 6 bar and the air flow is $100 \mathrm{lpm}$, VT produced $7.23^{\circ} \mathrm{C}$ lower temperature than the Non-VT. From Fig. 6 (b), it is clear that the VT cooling method produces the highest cooling rate in the first 20 minutes. At $t=80$ minutes, the conventional method had the highest cooling rate. This is due to the furnace temperature was still high comparing to NonVT and VT, which results in a higher temperature difference between the furnace and ambient. At $t=260$ minutes, the cooling rate of Non VT and VT is almost 0 . This shows that the furnace temperature is constant and almost equal to the ambient temperature. 


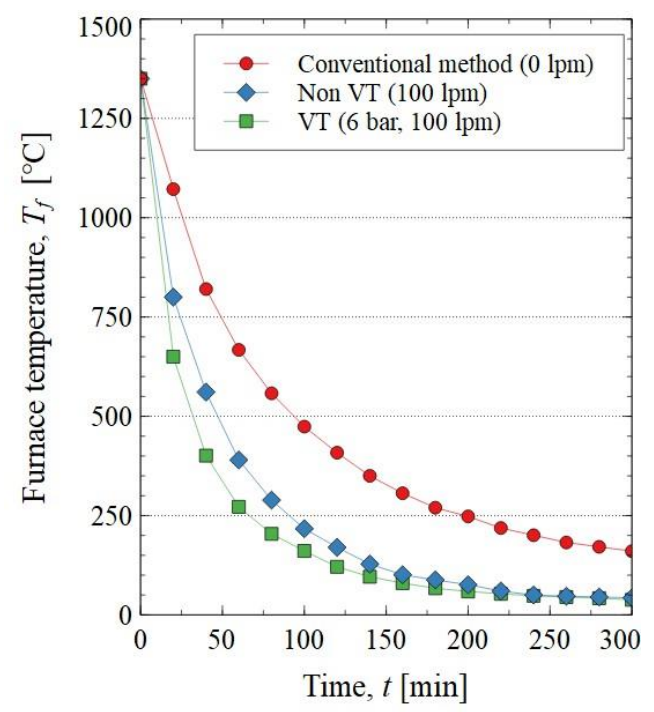

(a)

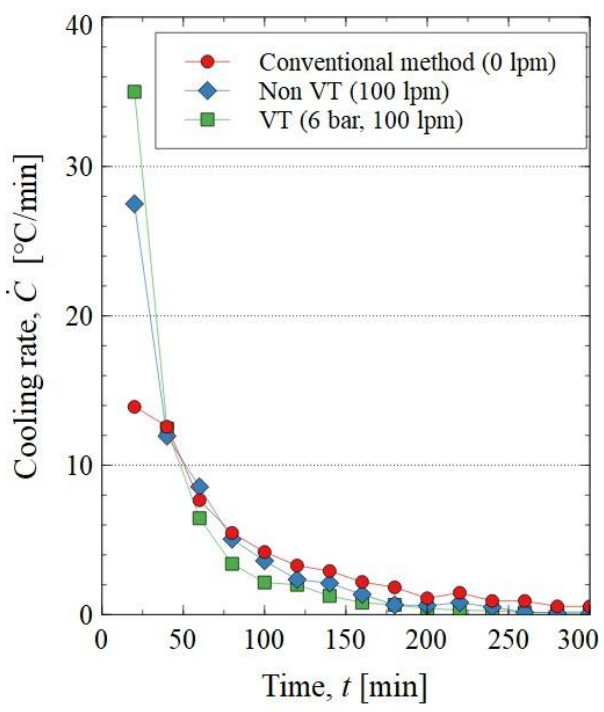

(b)

Fig. 6. Comparison of cooling methods; (a) Furnace temperature, (b) Cooling rate.

\subsection{Overall results for all parameters}

Fig. 7 shows the time required for all cooling methods to reduce the furnace temperature from $1350^{\circ} \mathrm{C}$ to $30^{\circ} \mathrm{C}$. The $\mathrm{x}$-axis represents the parameters of all cooling methods, and the y-axis represents the time taken until the furnace temperature is reduced to $30^{\circ} \mathrm{C}$.

From this figure, it can be understood that conventional method requires 580 minutes (9 hours 40 minutes) to reduce the furnace temperature to $30^{\circ} \mathrm{C}$. The lowest time required was obtained when using VT cooling method at inlet pressure of 6 bar and mass flow rate of $100 \mathrm{lpm}$, which is 410 minutes (6 hours 50 minutes). Compare to the conventional method, using VT cooling method reduced the cooling time up to 3 hours (170 minutes), which equals to $29.3 \%$ of cooling time reduction. It is also clear that increasing the mass flow rate reduces the cooling time for Non VT and VT. Compare to Non VT which use room temperature compressed air, using VT to decrease the compressed air temperature before entering the furnace is proven to be a better cooling method.

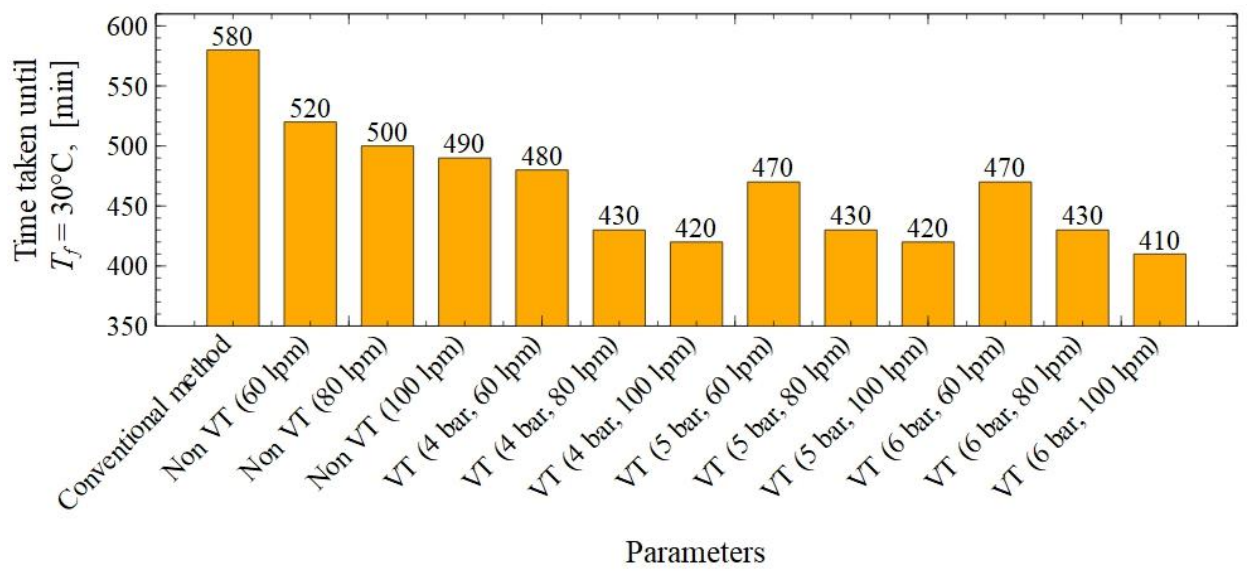

Fig. 7. Overall results for all parameters. 


\section{Conclusions}

Three cooling methods were compared to determine the best cooling method to reduce the high-temperature furnace from $1350^{\circ} \mathrm{C}$ to $30^{\circ} \mathrm{C}$. The first cooling method is the conventional method, which use the stagnant ambient air to reduce the temperature. The second method is using a room temperature compressed gas with $60 \mathrm{lpm}$ to $100 \mathrm{lpm}$ of flow. The last method is using a vortex tube, which can create a cold flow from a compressed gas. The conclusions are as follow:

1. The vortex tube produces the lowest cold flow temperature when the inlet pressure is $6 \mathrm{bar}$, and the flow rate is $100 \mathrm{lpm}$.

2. In the first 20 minutes, the cooling rate of VT cooling method is the highest.

3. Compare to the conventional method, using VT and Non VT cooling method reduce the cooling time up to 170 minutes and 90 minutes, respectively.

This research was supported by the Ministry of Higher Education and Universiti Malaysia Pahang under grant scheme RDU170137.

\section{References}

1. M. H. bin Yusof, H. Katanoda, MATEC Web Conf. 38, 01006 (2016).

2. S. E. Rafiee, M. M. M. Sadeghiazad, Appl. Therm. Eng. 114, 300 (2017).

3. G. S. Kumar, G. Padmanabhan, B. D. Sarma, Procedia Eng. 97, 828 (2014).

4. K. Devade, A. Pise, Energy Procedia 54, 642 (2014).

5. B. Markal, O. Aydin, M. Avci, O. Aydın, M. Avcı, Exp. Therm. Fluid Sci. 34, 966 (2010).

6. Y. Xue, M. Arjomandi, Exp. Therm. Fluid Sci. 33, 54 (2008).

7. S. U. Nimbalkar, M. R. Muller, Appl. Therm. Eng. (2009). 